\title{
Efficient Solar Cells Based on a Polymer Donor with $\beta$-Branching in Trialkylsilyl Side Chains
}

\author{
Haijun Bin ${ }^{a}$ (D) \\ Martijn M. Wienk ${ }^{\mathbf{a}}$ \\ René A. J. Janssen*a,b (D) \\ ${ }^{a}$ Molecular Materials and Nanosystems and Institute for Complex Molecular Systems, \\ Eindhoven University of Technology, P.O. Box 513, 5600 MB, Eindhoven, The \\ Netherlands \\ ${ }^{\mathrm{b}}$ Dutch Institute for Fundamental Energy Research, De Zaale 20, 5612 AJ, Eindhoven, \\ The Netherlands \\ r.a.j.janssen@tue.nl
}

Dedicated to Professor Peter Bäuerle on the occasion of his 65th birthday.

Received: 15.01.2021

Accepted after revision: 24.02.2021

DOI: 10.1055/s-0041-1726427; Art ID: om-21-0004oa

License terms: (c)

(c) 2021. The Author(s). This is an open access article published by Thieme under the terms of the Creative Commons Attribution-NonDerivative-NonCommercial License, permitting copying and reproduction so long as the original work is given appropriate credit. Contents may not be used for commercial purposes, or adapted, remixed, transformed or built upon. (https://creativecommons.org/licenses/by-nc-nd/4.0/)

Abstract Side-chain engineering is an important strategy in designing novel polymer semiconductor materials for high-efficient organic solar cells. The use of trialkylsilyl side chains can improve the photovoltaic efficiency by decreasing the energy of the HOMO of the polymer and improving its crystallinity and hole mobility. Compared to simple linear derivatives, $\alpha$-branching in the alkyl groups of trialkylsilyl side chains causes strong aggregation and excessive phase separation in the photoactive layer, leading to poor device performance. $\beta$-Branching of the alkyl groups has not yet been used in trialkylsilyl side chains. Herein, we describe a new polymer (J77) with triisobutylsilyl side chains to investigate the effect of $\beta$-branching on the molecular aggregation, optical properties, energy levels, and photovoltaic properties. We find that compared to $\alpha$-branching, $\beta$-branching of alkyl groups in trialkylsilyl side chains significantly reduces aggregation. This enables $\mathrm{J} 77$ to form blend morphologies in films that provide high-efficient solar cells in combination with different non-fullerene acceptors. Moreover $\beta$ branching of the alkyl groups in trialkylsilyl side chains lowers the HOMO energy level of $\mathrm{J77}$ and increases the open-circuit voltage of $\mathrm{J77}$ based solar cells without sacrificing short-circuit current density or fil factor.

Key words organic solar cells, polymer donors, non-fullerene acceptors, cross-coupling, power conversion efficiencies

\section{Introduction}

Organic solar cells comprise donor and acceptor semiconductors in which holes and electrons are generated under illumination. Both small molecules, ${ }^{1}$ well-defined

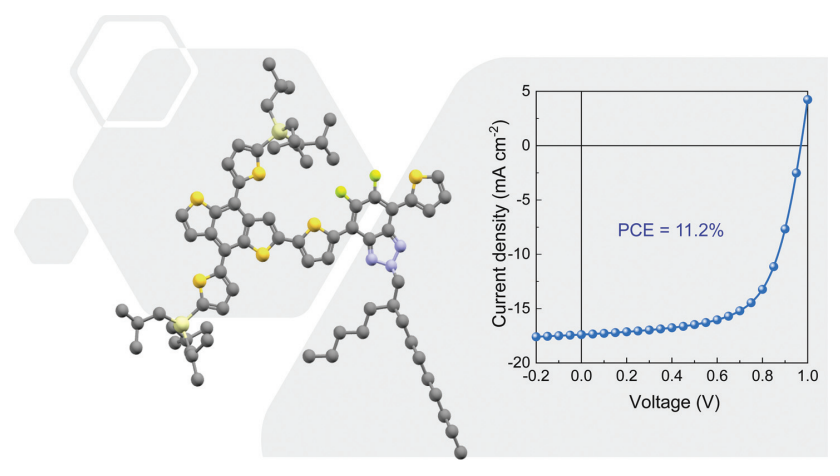

dendrimers, ${ }^{2}$ and $\pi$-conjugated polymers ${ }^{3}$ have been used for this purpose. In recent years, polymer solar cells (PSCs) composed of $p$-type $\pi$-conjugated donor polymers and $n$ type non-fullerene acceptors (NFAs) have blossomed. Numerous efficiency breakthroughs in combination with advantages such as potential low cost, lightweight, and flexibility make PSCs continue to attract vivid attention. ${ }^{4-7}$ Benefiting from the new materials and advanced device engineering, the power conversion efficiency (PCE) of single-junction and tandem PSCs now exceeds $17 \% .^{8-14}$ The design and synthesis of polymer donors play an important role in obtaining high PCEs. ${ }^{15-19}$ Traditionally, the main focus of researchers has been on the design and synthesis of new building blocks to develop the main chain of the polymer donor, while side chains were merely regarded to improve solubility. However, more and more studies suggest that the type, size, topology, and distribution of side chains have a great influence on the aggregation, $\pi$-stacking, orientation, optical properties, charge transport, and photovoltaic properties of these materials. Therefore, side-chain engineering is now widely explored in the design of novel semiconductors for high-efficient organic solar cells. $^{20-34}$

Side-chain engineering is also an important design strategy to reduce energy and voltage losses in PSCs, which remains a crucial issue in comparison to silicon and perovskite solar cells. ${ }^{18,22,23,32,35,36}$ A common approach to lower the energy loss of PSCs is to narrow the energy level offsets of the HOMOs and LUMOs of the donor and acceptor in the active layer, while ensuring effective charge separation. ${ }^{37-40}$ As an example, in a recent study, a series of wide bandgap benzodithiophene-alt-difluorobenzotriazole (BDTT-alt-FBTA) copolymers with trialkylsilyl side chains was compared with alkyl side-chain analogs. ${ }^{41}$ Trialkylsilyl side chains efficiently decrease the HOMO energy and improve crystallinity and hole mobility of the polymer, while keeping an extraordinarily high exciton dissociation 


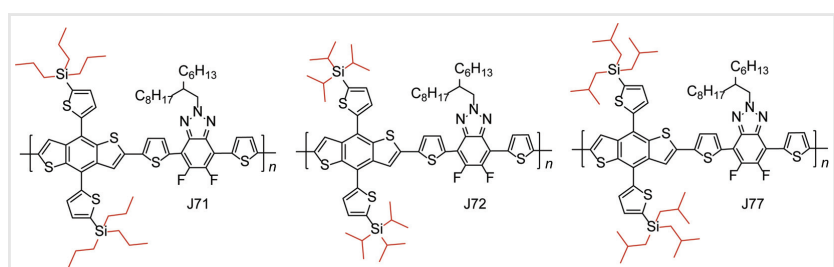

Figure 1 Benzodithiophene-alt-difluorobenzotriazole (BDTT-alt-FBTA) copolymers (J71, J72, J77) with different trialkylsilyl side chains.

and charge separation efficiency. ${ }^{41}$ This simultaneously improved the open-circuit voltage $\left(V_{\mathrm{oc}}\right)$ and the shortcircuit current density $\left(J_{\mathrm{sc}}\right)$, and thereby the PCE. ${ }^{41}$ In comparing the effect of linear and $\alpha$-branched alkyl groups in the trialkylsilyl side chains on the photovoltaic properties, it was found that the linear propyl groups afford more ordered molecular packing, higher absorption coefficients, and higher charge carrier mobility than $\alpha$-branched isopropyl groups. As a result, a BDTT-alt-FBTA copolymer with tripropylsilyl side chains (J71) showed higher $J_{\mathrm{sc}}$ and fill factor (FF) in PSCs than the corresponding copolymer (J72) with triisopropylsilyl side chains (Figure 1). ${ }^{24}$ Remarkably, the isopropyl groups did not provide J72 with a lower tendency to aggregate or higher solubility. Bulk heterojunction films based on J72 with NFAs showed excessive phase segregation, resulting in a lower $J_{\mathrm{sc}}$ and FF than for the corresponding J71-based devices. ${ }^{24}$

$\beta$-Branched alkyl chains are the most commonly employed side chains for $\pi$-conjugated polymers and have been widely used in efficient photovoltaic materials because they offer a good trade-off between molecular solubility and molecular order. ${ }^{20,23,26,33,42,43}$ However, so far $\beta$-branched alkyl groups in trialkylsilyl side chains have not been studied. To fill this gap, we designed and synthesized a BDTT-alt-FBTA copolymer (J77, Figure 1) with $\beta$-branched isobutyl groups in the trialkysilyl side chains and investigated the effect on the molecular aggregation, optical absorption, energy levels, and photovoltaic properties. We find that triisobutylsilyl side chains reduce the tendency of the polymer to aggregate and offer enhanced solubility compared to triisopropylsilyl. Moreover, J77 presents a lower HOMO level and gives better device performance after blending with a variety of NFAs than J71. The results illustrate that $\beta$-branching of alkyl groups in trialkylsilyl side chains is a promising approach to create polymer donors for efficient PSCs.

\section{Results and Discussion}

The synthesis of J77 was accomplished by a palladiumcatalyzed cross-coupling reaction (Scheme 1). Benzo[1,2$b: 4,5-b]$ dithiophene-4,8-dione and compounds 1-4 were synthesized following procedures analogous to those

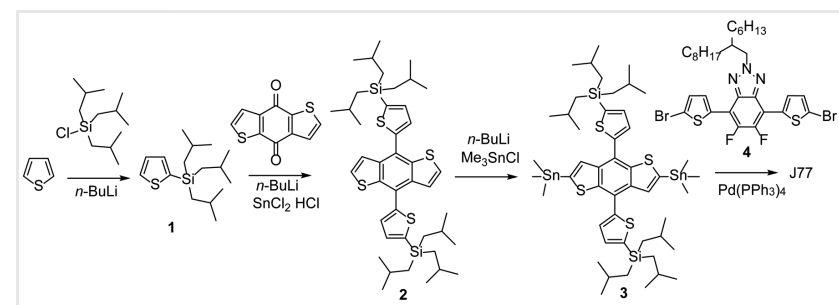

Scheme 1 Synthesis route to polymer J77.

reported in the literature. ${ }^{41,43}$ The synthetic procedures and details of the characterization are described in the Experimental Section. J77 shows good solubility in common organic solvents such as chloroform and chlorobenzene. Likewise, compounds $\mathbf{2}$ and $\mathbf{3}$ show good solubility which is favorable for their purification. The molecular weight distribution of $\mathrm{J77}$ was measured by gel permeation chromatography (GPC) in 1,2-dichlorobenzene (o-DCB) as the eluent, calibrated by polystyrene internal standards. The number-average molecular weight $\left(M_{\mathrm{n}}\right)$ of $\mathrm{J} 77$ is $30.2 \mathrm{kDa}$ with a polydispersity of 2.53 .

As can be expected, J77 and J71 exhibit similar absorption spectra (Figure 2a), covering the range of 400 to $650 \mathrm{~nm}$, with a maximum at $\sim 536 \mathrm{~nm}$ and a clear vibrionic structure that indicates $\pi-\pi$ stacking between the polymer backbones. However, compared to J71, the absorption spectrum of J77 is slightly blue-shifted and the $0-0$ vibrionic peak is somewhat less intense. This suggests a relatively less ordered intermolecular stacking, which is tentatively ascribed to a higher steric hindrance of the $\beta$-branched isobutyl groups that hamper co-planarity of the polymer main chain in J77 more than the linear propyl groups do in J71.J77 displays an absorption onset at $622 \mathrm{~nm}$ corresponding to a relatively wide optical bandgap of $1.99 \mathrm{eV}$.

The HOMO and LUMO levels of J71 and J77 were determined by cyclic voltammetry on thin films immersed in a $0.1 \mathrm{M}$ solution of tetrabutylammonium hexafluorophosphate $\left(n-\mathrm{Bu}_{4} \mathrm{NPF}_{6}\right)$ in acetonitrile (Figure $\left.2 \mathrm{~b}\right)$. The HOMO and LUMO levels were calculated from the onset potentials of the oxidation and reduction waves and were found to be -5.26 and $-3.63 \mathrm{eV}$ for $\mathrm{J} 71$ and -5.31 and
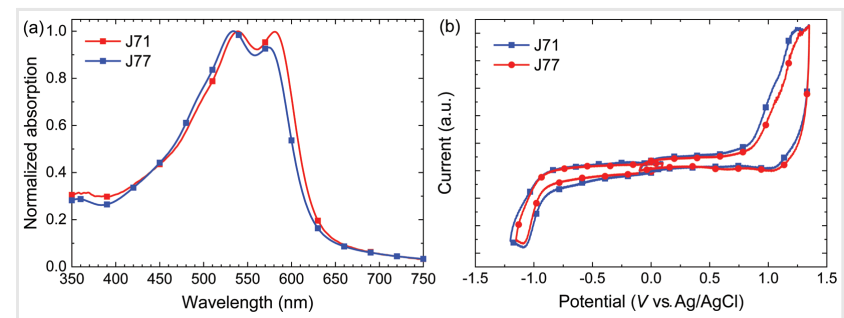

Figure 2 (a) Optical absorption spectra of J71 and J77. (b) Cyclic voltammograms of $\mathrm{J} 71$ and $\mathrm{J77.}$ 


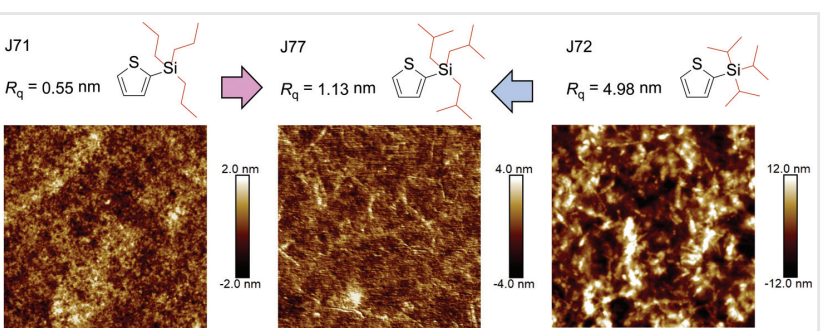

Figure 3 AFM height images of pristine films of J71, J72, and J77. Image size is $3 \mu \mathrm{m} \times 3 \mu \mathrm{m}$.

$-3.58 \mathrm{eV}$ for $\mathrm{J} 77$, respectively. Hence, the $\beta$-branched isobutyl groups provide a slightly deeper HOMO level to $\mathrm{J} 77$, which can contribute higher $V_{\text {oc }}$ in a solar cell.

The thin-film aggregation behavior of the pristine polymers was investigated using atomic force microscopy (AFM) in tapping mode. As shown in Figure 3, spin-coated films of J71 with tripropylsilyl side chains have a very smooth and uniform surface topology with a small rootmean-square surface roughness $\left(R_{\mathrm{q}}\right)$ of $0.55 \mathrm{~nm}$. In contrast, for J72, with triisopropylsilyl side chains, the surface roughness is almost 1 order of magnitude higher $\left(R_{\mathrm{q}}=4.98\right.$ $\mathrm{nm})$ and there are clear signs of aggregates in the height image. By adjusting the branching to the $\beta$-position, the new copolymer J77 with its triisobutylsilyl side chains shows a $R_{\mathrm{q}}$ of $1.13 \mathrm{~nm}$. Hence, the aggregation tendency of J77 has been suppressed compared to J72, which is favorable to the formation of suitable phase separation and morphology in blend films with NFAs. The suppressed aggregation of $\mathrm{J77}$ compared to $\mathrm{J} 72$ is ascribed to an enhanced conformational freedom and larger flexibility provided by $\beta$-branched isobutylsilyl groups, thereby providing a better solubility and lower tendency to crystallize than the $\alpha$-branched isopropylsilyl side chains which are shorter and conformationally more rigid. Consequently, triisopropylsilyl side chains contribute less to the solubility of the polymer than triisobutylsilyl side chains, leading to an enhanced aggregation.

To explore the effect of $\beta$-branching in the triisobutylsilyl side chains on the photovoltaic properties, we employed four different NFAs (ITIC, m-ITIC, IT-4F, and IDIC) (Figure 4) in blends with J77 and made PSCs using a conventional device architecture consisting of an ITO/PEDOT:PSS/J77:NFA/ PDINO/Al layer stack. The donor and acceptor components in the blend films offer complementary absorption spectra and together cover the $\sim 400-$ $800 \mathrm{~nm}$ spectral range (Figure $5 \mathrm{a}$ ). The energy level diagram of J77 and the four NFAs shows energy level offsets that are suitable to effectively dissociate excitons (Figure 5b). The optimal conditions for highest solar cell performance were found to be a donor-acceptor blend weight ratio of $1: 1$, using a total concentration of $20 \mathrm{mg} \mathrm{mL}^{-1}$ in chloroform, and spin coating the solution at $2000 \mathrm{rpm}$. Thermal

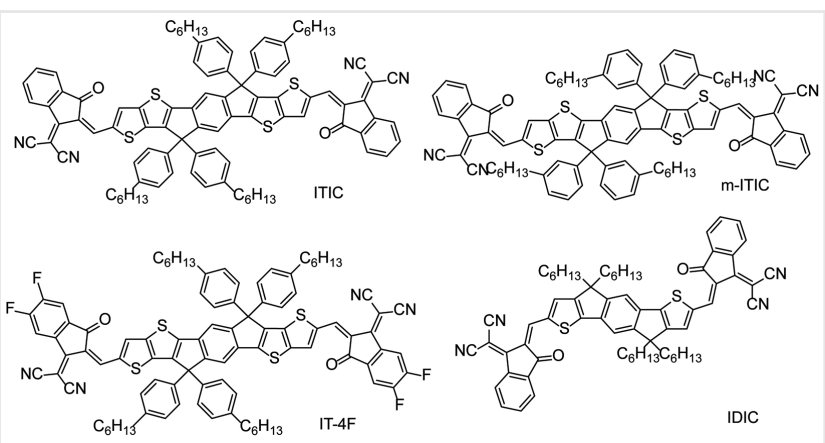

Figure 4 Molecular structures of the NFAs used in this study.
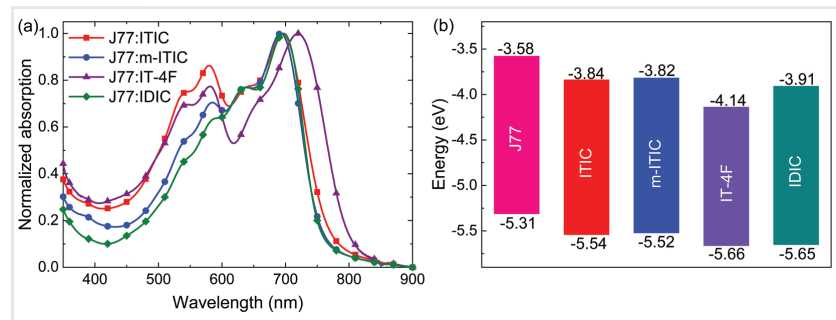

Figure 5 (a) Absorption spectra of blends of 777 with NFAs. (b) Energy level diagram.

annealing was used to optimize the device performance $\left(150{ }^{\circ} \mathrm{C}\right.$ for $10 \mathrm{~min}$ for ITIC- and $\mathrm{m}$-ITIC-based devices, $120^{\circ}$ $\mathrm{C}$ for $5 \mathrm{~min}$ for IT-4F-based devices, and $150^{\circ} \mathrm{C}$ for $2 \mathrm{~min}$ for IDIC-based devices).

The current density-voltage $(J-V)$ characteristics of the solar cells reveal PCEs $\geq 10 \%$ for $\mathrm{J} 77$ in combination with all four NFAs (Figure 6a, Table 1). The J77:ITIC blend provides a PCE of $10.5 \%$ with a high $V_{\text {oc }}$ of $0.98 \mathrm{~V}$, a $J_{\text {sc }}$ of
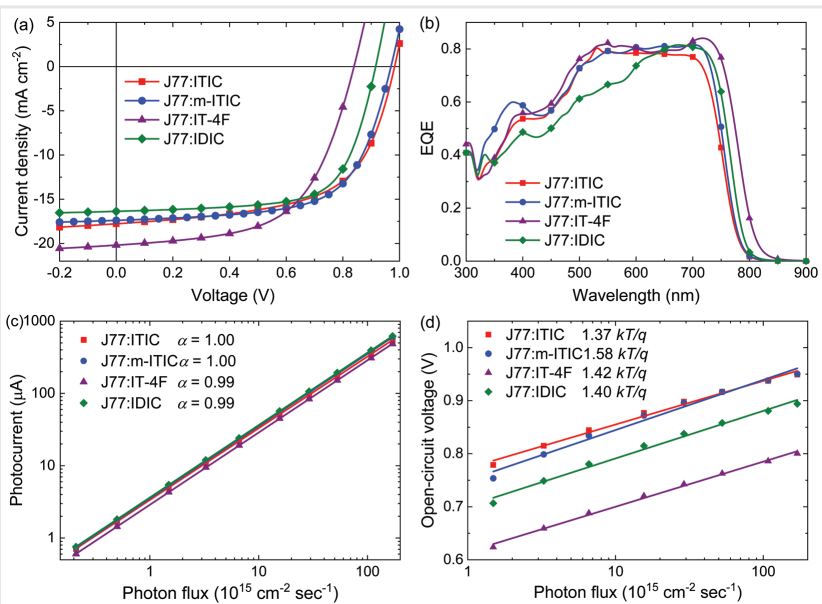

Figure 6 Optimized J77:NFA PSCs. (a) J - V characteristics under simulated AM1.5G (100 mW cm${ }^{-2}$ ) illumination. (b) EQE spectra. (c) Dependence of $\int_{\mathrm{sc}}$ on photon flux. (d) Dependence of $V_{\mathrm{oc}}$ on photon flux. 
Table 1 Photovoltaic parameters of J77:NFA PSCs under simulated AM1.5G $\left(100 \mathrm{~mW} \mathrm{~cm}{ }^{-2}\right)$ illumination

\begin{tabular}{|c|c|c|c|c|c|c|c|c|}
\hline Device & $V_{\mathrm{oc}}(\mathrm{V})$ & $J_{\mathrm{sc}}\left(\mathrm{mA} \mathrm{cm}{ }^{-2}\right)$ & $\mathrm{FF}$ & PCE (\%) & $\int_{\mathrm{sc}}{ }^{\mathrm{a}}\left(\mathrm{mA} \mathrm{cm}{ }^{-2}\right)$ & $\mu_{\mathrm{h}}\left(\mathrm{cm}^{2} \mathrm{v}^{-1} \mathrm{~s}^{-1}\right)$ & $\mu_{e}\left(\mathrm{~cm}^{2} \mathrm{v}^{-1} \mathrm{~s}^{-1}\right)$ & $\mu_{\mathrm{h} / \mu_{\mathrm{e}}}$ \\
\hline J77:ITIC & 0.98 & 17.8 & 0.60 & 10.5 & 17.4 & $1.54 \times 10^{-4}$ & $1.14 \times 10^{-4}$ & 1.35 \\
\hline J77:m-ITIC & 0.97 & 18.1 & 0.64 & 11.2 & 17.4 & $1.70 \times 10^{-4}$ & $1.46 \times 10^{-4}$ & 1.16 \\
\hline J77:IT-4F & 0.84 & 20.2 & 0.59 & 10.0 & 19.6 & $1.14 \times 10^{-4}$ & $0.48 \times 10^{-4}$ & 2.37 \\
\hline J77:IDIC & 0.92 & 17.0 & 0.68 & 10.6 & 16.4 & $1.84 \times 10^{-4}$ & $1.82 \times 10^{-4}$ & 1.01 \\
\hline
\end{tabular}

antegrated from the EQE spectrum.

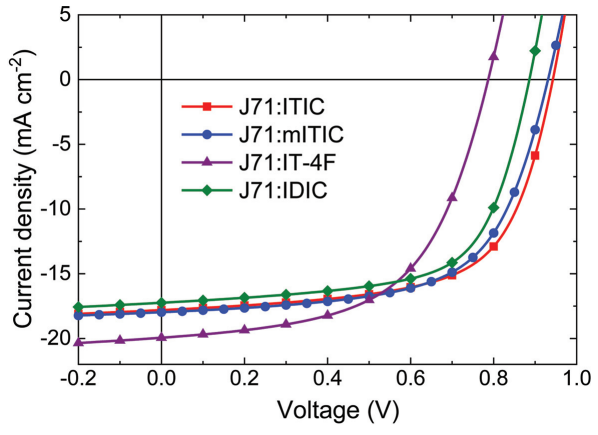

Figure $7 \mathrm{~J}-V$ characteristics of optimized J71:NFA PSCs under simulated AM1.5G $\left(100 \mathrm{~mW} \mathrm{~cm}^{-2}\right)$ illumination.

$17.8 \mathrm{~mA} \mathrm{~cm}^{-2}$, and a FF of 0.60 . Changing the acceptor to m-ITIC improved the PCE to $11.2 \%$, mainly because of an increased FF of 0.64. For the J77:IT-4F blend, the PCE is $10.0 \%$. Here the lower optical bandgap improved $J_{\mathrm{sc}}$ $\left(20.2 \mathrm{~mA} \mathrm{~cm}^{-2}\right)$, but lowered $V_{\text {oc }}(0.84 \mathrm{~V})$ and $\mathrm{FF}(0.59)$. Finally for the IDIC-based device, the PCE reached to $10.6 \%$, with a high $V_{\text {oc }}$ of $0.92 \mathrm{~V}$, a $J_{\mathrm{sc}}$ of $17.02 \mathrm{~mA} \mathrm{~cm}^{-2}$, and a FF of 0.68. For a direct comparison, we also fabricated the devices using J71 as the donor (Figure 7, Table 2). The ITICbased devices show comparable performance for J77 $(\mathrm{PCE}=10.5 \%)$ and $\mathrm{J71}(\mathrm{PCE}=10.7 \%)$, but $\mathrm{m}-\mathrm{ITIC}, \mathrm{IT}-4 \mathrm{~F}$, and IDIC devices with J77 (PCE $=11.2 \%, 10.0 \%, 10.6 \%)$ were always better than with J71 ( $\mathrm{PCE}=10.4 \%, 8.8 \%, 10.0 \%)$. The improved PCE for J77 compared to J71 is primarily due to a higher $V_{\mathrm{oc}}$, but without sacrificing $J_{\mathrm{sc}}$ or FF. These results indicate that the introduction of $\beta$-branching in the triisobutylsilyl side chains in J77 effectively reduces the

Table 2 Photovoltaic parameters of J71:NFA PSCs under simulated AM1.5G $\left(100 \mathrm{~mW} \mathrm{~cm}^{-2}\right)$ illumination

\begin{tabular}{lllll}
\hline Device & $V_{\text {oc }}(\mathrm{V})$ & $J_{\text {sc }}\left(\mathrm{mA} \mathrm{cm}^{-2}\right)$ & FF & PCE $(\%)$ \\
\hline J71:ITIC & 0.94 & 17.8 & 0.64 & 10.7 \\
J71:m-ITIC & 0.93 & 18.0 & 0.62 & 10.4 \\
J71:IT-4F & 0.79 & 19.9 & 0.56 & 8.8 \\
J71:IDIC & 0.89 & 17.2 & 0.65 & 10.0 \\
\hline
\end{tabular}

HOMO energy level with negligible negative effects on the charge generation and collection efficiency of the blends.

The corresponding external quantum efficiency (EQE) spectra (Figure $6 \mathrm{~b}$ ) reach up to $80 \%$ and cover a broad wavelength range of $300-800 \mathrm{~nm}$, demonstrating that both donor and acceptor contribute to the $J_{\mathrm{sc}}$ of the PSCs. The $J_{\mathrm{sc}}$ values integrated from the EQE spectra agree well with the values obtained from the $J-V$ curves with less than $5 \%$ mismatch (Table 1). To examine charge recombination in J77:NFA blends, the dependence of $J_{\mathrm{sc}}$ and $V_{\mathrm{oc}}$ on the incident photon flux $(\Phi)$ was investigated. In general the short-circuit current density follows a power-law dependence with photon flux $\left(J_{s c} \propto \Phi^{\alpha}\right)$. For the four devices, the exponent $\alpha$ was found to be almost unity (Figure $6 \mathrm{c}$ ), indicating that at short-circuit bimolecular recombination is negligible. ${ }^{44}$ The dependence of $V_{\text {oc }}$ on light intensity was measured to study the balance between bimolecular and surface recombination on one hand and trap-assisted recombination on the other. If trap-assisted recombination is very weak or negligible, the slope of $V_{\text {oc }}$ vs. the natural logarithm of photon flux ( $\ln \Phi$ ) is close to $k T / q$, where $k$ is the Boltzmann constant, $T$ the absolute temperature, and $q$ the elementary charge. ${ }^{44}$ The slopes were found to be 1.37 $k T / q, 1.58 k T / q, 1.42 k T / q$, and $1.40 k T / q$ for ITIC-, m-ITIC-, IT$4 \mathrm{~F}-$, and IDIC-based devices, respectively (Figure $6 \mathrm{~d}$ ). These results demonstrate that in all devices trap-assisted recombination occurs.

Hole-only (ITO/PEDOT:PSS/J77:NFA/ $\mathrm{MoO}_{3} / \mathrm{Ag}$ ) and electron-only (ITO/ZnO/J77:NFA/PDINO/Al) devices were used to investigate the charge transport properties of J77:NFA blends, by determining the hole and electron mobilities from the space-charge-limited current (SCLC; Figure 8 , Table 1). For the four J77:NFA blends, the hole mobilities $\left(\mu_{\mathrm{h}}\right)$ are $1.56 \pm 0.30 \times 10^{-4} \mathrm{~cm}^{2} \mathrm{~V}^{-1} \mathrm{~s}^{-1}$, while the electron mobilities $\left(\mu_{\mathrm{e}}\right)$ are $1.23 \pm 0.57 \times 10^{-4} \mathrm{~cm}^{2} \mathrm{~V}^{-1}$ $\mathrm{s}^{-1}$ and thus slightly lower and vary more. The $\mu_{\mathrm{h}} / \mu_{\mathrm{e}}$ ratio, however, varies in accordance with FF and is closest to unity $\left(\mu_{\mathrm{h}} / \mu_{\mathrm{e}}=1.01\right)$ for J77:IDIC, where FF $=0.68$ and deviates most from unity $\left(\mu_{\mathrm{h}} / \mu_{\mathrm{e}}=2.37\right)$ for J77:IT-4F, where FF $=0.59$. The higher and more-balanced charge carrier mobilities in the J77:IDIC blend are beneficial to charge separation and charge transport, and contribute to a higher FF of 0.68 . 

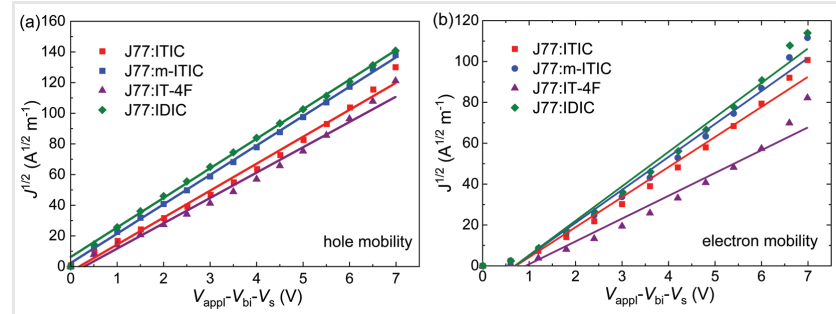

Figure $8 \boldsymbol{J}^{1 / 2}$ versus $V_{\mathrm{appl}}-V_{\mathrm{bi}}-V_{\mathrm{s}}$ for J77:NFA blends. (a) For hole devices. (b) For electron-only devices. $V_{\text {appl }}$ is the applied voltage, $V_{\mathrm{bi}}$ is the built-in voltage, and $V_{\mathrm{s}}$ the voltage loss as a consequence of the series resistance.

To identify the microstructure and characterize the surface morphology of the active layers of the four J77:NFA blend films, tapping-mode AFM was performed (Figure 9). All films present a relatively smooth surface, consistent with an intimately mixed blend and absence of coarse phase separation. For the blends of $\mathrm{J77}$, the $R_{\mathrm{q}}$ values range from 0.99 to $2.57 \mathrm{~nm}$ (Figure 9) and are very close to those of the corresponding J71-based films where $R_{\mathrm{q}}$ varies between 0.55 and $1.91 \mathrm{~nm}$ as shown in the Supporting Information (Figure S1). The sub-nanometer surface roughness found for J71:ITIC $\left(R_{\mathrm{q}}=0.55 \mathrm{~nm}\right)$ and J71:IT$4 \mathrm{~F}\left(R_{\mathrm{q}}=0.80 \mathrm{~nm}\right)$ agrees well with previously reported data for these blends of 0.72 and $0.74 \mathrm{~nm}$, respecively. ${ }^{41,45}$ Compared to the J77-based blend films, the $R_{\mathrm{q}}$ values of the J71-based blend film are thus slightly lower, but the difference is very small. This suggests that similar nanophase morphology is obtained with triisobutylsilyl side chains as with tripropylsilyl side chains. The largest $R_{\mathrm{q}}$ value $(2.37 \mathrm{~nm})$ was found for the J77:IDIC blend film, but the surface does not show signs of aggregates or extensive phase separation. These results further confirm that compared to $\alpha$-branching, $\beta$-branching in alkyl groups of trialkylsilyl side chains effectively reduces the aggregation of polymer chains.

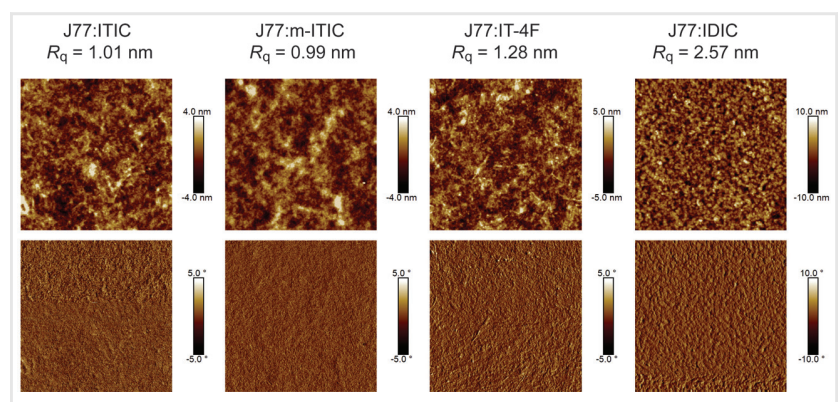

Figure 9 Tapping mode AFM ( $3 \mu \mathrm{m} \times 3 \mu \mathrm{m})$ height (top row) and phase (bottom row) images of the J77:NFA blends.

\section{Conclusions}

In summary, a new BDTT-alt-FBTA-based wide bandgap polymer donor J77 with triisobutylsilyl side chains was developed and successfully applied in efficient PSCs with narrow-bandgap NFAs. Compared to triisopropylsilyl side chains with $\alpha$-branched alkyl groups, the $\beta$-branched isobutyl groups significantly reduce the aggregation of the polymer. As a result, J77 forms an appropriate phase separation and morphology in the blend film for high photovoltaic performance. Importantly, the $\beta$-branching further lowered the HOMO energy level of J77 compared to J71 with linear alkyl groups, while keeping its favorable characteristics in terms of mobility and charge generation and transport. As a result, J77:NFA-based solar cells afford higher $V_{\mathrm{oc}}$ without losing $J_{\mathrm{sc}}$ and FF, compared to the J71:NFA cells. We envision that incorporation of $\beta$-branched alkyl groups in trialkylsilyl side chains is a useful strategy for the design of efficient photovoltaic donor materials.

\section{Experimental Section}

All chemicals and solvents were purchased from Sigma Aldrich, Alfa Aesar, or TCI Chemical Co. ${ }^{1} \mathrm{H}$ NMR spectra were measured on a Bruker AVANCE III HD $400 \mathrm{MHz}$ spectrometer with $d$-chloroform as the solvent and tetramethylsilane as the internal reference. Matrix-assisted laser desorption ionization time of flight (MALDI-TOF) mass spectrometry was performed on a Bruker Autoflex Speed spectrometer. Polymer molecular weight distributions were estimated by GPC at $140^{\circ} \mathrm{C}$ on a PL-GPC 120 system using a PL-GEL $10 \mu \mathrm{m}$ MIXED-C column with $o$-DCB as the eluent. Molecular weights were calibrated against polystyrene internal standards. Samples were dissolved in 0 -DCB at $140{ }^{\circ} \mathrm{C}$ at a concentration of $0.1 \mathrm{mg} \mathrm{mL}^{-1}$. UV-vis-near IR spectroscopy was recorded on a PerkinElmer Lambda 1050 UV-vis-near IR spectrophotometer at room temperature. Cyclic voltammetry studies were performed with a scan rate of $0.1 \mathrm{~V} \mathrm{~s}^{-1}$ under an inert atmosphere with $1 \mathrm{M} \mathrm{n}-\mathrm{Bu}_{4} \mathrm{NPF}_{6}$ in acetonitrile as the electrolyte. All potentials are reported versus the ferrocene/ferrocenium redox couple $\left(\mathrm{Fc} / \mathrm{Fc}^{+}\right)$and a value of $-4.8 \mathrm{eV}$ was used to convert redox potentials to energies vs. vacuum. The morphologies of films were characterized by a Veeco Dimension 3100 atomic force microscope with tapping mode.

\section{Triisobutyl(thiophen-2-yl)silane (1)}

Under a protective argon atmosphere, $n$-BuLi $(20 \mathrm{~mL}$, $2.5 \mathrm{M}$ in hexane) was slowly added to a solution of thiophene $(4.2 \mathrm{~g}, 50 \mathrm{mmol})$ in THF $(100 \mathrm{~mL})$ at $-78{ }^{\circ} \mathrm{C}$, the mixture was kept at $-78{ }^{\circ} \mathrm{C}$ for $1 \mathrm{~h}$ and subsequently 
slowly warmed to room temperature. Then, chlorotriisobutylsilane (11.7 g, $50 \mathrm{mmol}$ ) was added, and the mixture was stirred overnight. The mixture was extracted twice using diethyl ether, and washed with water and brine. Removal of the solvent by rotary evaporation under reduced pressure afforded a colorless liquid that was used without further purification.

\section{4,8-Bis(5-(triisobutylsilyl)thiophen-2-yl)benzo[1,2- $b: 4,5-b$ ']dithiophene (2)}

Under argon protection, $n$-BuLi (12 mL, $2.5 \mathrm{M}$ in hexane) was slowly added to a solution of compound 1 (8.4 g, $30 \mathrm{mmol})$ in THF $(30 \mathrm{~mL})$ at $0{ }^{\circ} \mathrm{C}$. The mixture was kept at $0{ }^{\circ} \mathrm{C}$ for 15 min then warmed to $50{ }^{\circ} \mathrm{C}$ and stirred for $2 \mathrm{~h}$. Benzo [1,2-b:4,5-b]dithiophene-4,8-dione $(2.2 \mathrm{~g}, 10 \mathrm{mmol})$ was added quickly, and the mixture stirred for $2 \mathrm{~h}$. After cooling to the room temperature, $\mathrm{SnCl}_{2} \cdot 2 \mathrm{H}_{2} \mathrm{O}(18 \mathrm{~g}, 80 \mathrm{mmol}$ ) in $10 \%$ $\mathrm{HCl}(35 \mathrm{~mL})$ was added, and the mixture was stirred for $3 \mathrm{~h}$. Then the mixture was extracted twice using diethyl ether, and washed with water and brine. The crude product was purified by column chromatography using heptane as the eluent to obtain pure compound 2 as a light yellow solid (4.2 g, 56\% yield). ${ }^{1} \mathrm{H} \mathrm{NMR}\left(400 \mathrm{MHz}, \mathrm{CDCl}_{3}\right), \delta(\mathrm{ppm}): 7.59-7.58(\mathrm{~d}, 2 \mathrm{H})$, 7.53-7.52 (d, $2 \mathrm{H}), 7.46-7.45$ (d, $2 \mathrm{H}), 7.38-7.37$ (d, $2 \mathrm{H})$, 1.93-1.88 (m, 6 H), 0.98-0.92 (m, 48 H). MALDI-TOF MS: calcd. for $\mathrm{C}_{42} \mathrm{H}_{62} \mathrm{~S}_{4} \mathrm{Si}_{2}: m / z=750.33$; found 750.34 .

\section{((2,6-Bis(trimethylstannyl)benzo[1,2-b:4,5-b'] dithiophene-4,8-diyl)bis(thiophene-5,2-diyl))bis (triisobutylsilane) (3)}

To a solution of $2(1.50 \mathrm{~g}, 2 \mathrm{mmol})$ in THF $(20 \mathrm{~mL})$ at -78 ${ }^{\circ} \mathrm{C}$ was added $n$-BuLi (2 mL, $2.5 \mathrm{M}$ in hexane). After addition, the mixture was kept at $-78{ }^{\circ} \mathrm{C}$ for $40 \mathrm{~min}$; trimethyltin chloride ( $6 \mathrm{~mL}, 1 \mathrm{M}$ in THF) was added dropwise. The resulting mixture was stirred for $2 \mathrm{~h}$ at room temperature. Then it was poured into water and extracted with diethyl ether, washed with water and brine, and after drying over $\mathrm{Mg}_{2} \mathrm{SO}_{4}$, the solvent was removed and the residue was recrystallized with methanol to afford yellow crystals (1.62 g, 75\% yield) . ${ }^{1} \mathrm{H}$ NMR (400 $\left.\mathrm{MHz}, \mathrm{CDCl}_{3}\right), \delta(\mathrm{ppm})$ : 7.65 (s, 2 H), 7.56-7.55 (d, 2 H), 7.38-7.37 (d, 2 H), 1.96-1.89 (m, $6 \mathrm{H}), 0.99-0.93(\mathrm{~m}, 48 \mathrm{H}), 0.45-0.31(\mathrm{t}, 18 \mathrm{H})$. MALDITOF MS: calcd. for $\mathrm{C}_{48} \mathrm{H}_{78} \mathrm{~S}_{4} \mathrm{Si}_{2} \mathrm{Sn}_{2}: m / z=1076.98$; found 1076.26 .

\section{Synthesis of $\mathbf{J 7 7}$}

Compounds 3 (269 mg, $0.25 \mathrm{mmol}$ ), 4 (175 mg, $0.25 \mathrm{mmol})$, and dry toluene $(10 \mathrm{~mL})$ were added to a
$50 \mathrm{~mL}$ Schlenk tube. The Schlenk tube was purged with argon for $20 \mathrm{~min}$ and then $\mathrm{Pd}\left(\mathrm{PPh}_{3}\right)_{4}(10 \mathrm{mg})$ was added. After another flushing with argon for $20 \mathrm{~min}$, the reaction mixture was heated to reflux for $12 \mathrm{~h}$. The reaction mixture was then cooled to room temperature and poured into $\mathrm{MeOH}(200 \mathrm{~mL})$ and filtered through a Soxhlet thimble. The residue was then subjected to Soxhlet extraction with methanol, hexane, and chloroform. The polymer was recovered from the chloroform fraction by precipitation from methanol. The solid was dried under vacuum and obtained as black solid (278 mg, 92\% yield).

\section{Device Fabrication and Characterization}

PSCs were fabricated and characterized in a $\mathrm{N}_{2}$-filled glovebox. Pre-patterned indium tin oxide (ITO)-coated glass substrates were cleaned in acetone and isopropyl alcohol for 10 min each. After drying, the substrates were coated with $40 \mathrm{~nm}$ poly(3,4-ethylenedioxythiophene) polystyrene sulfonate (PEDOT:PSS) (Heraeus, Clevios P VP.Al 4083) via spin coating. The active layer was spin-coated in a $\mathrm{N}_{2}$-filled glovebox. 2,9-Bis[3-(dimethyloxidoamino)propyl]anthra [2,1,9-def:6,5,10-d'e'f']diisoquinoline-1,3,8,10(2H,9H)tetrone (PDINO, CAS No.: 1558023-86-1) was deposited atop the active layer as an electrode interlayer via spin coating from a $1.0 \mathrm{mg} \mathrm{mL}^{-1}$ solution in methanol. Finally, an Al top electrode was deposited by thermal evaporation in vacuum onto the PDINO buffer layer at a pressure of $\sim 5.0 \times 10^{-7} \mathrm{~Pa}$. The $J-V$ characteristics and EQE spectra of the PSCs were recorded as described previously. ${ }^{45}$

\section{Mobility Measurement}

The hole and electron mobilities were determined by fitting the experimental current density-voltage characteristics to the Murgatroyd relation: $J=(9 / 8) \varepsilon_{0} \varepsilon_{\mathrm{r}} \mu_{0}\left(V^{2} / L^{3}\right)$ $\exp \left[0.89 \gamma(V / L)^{1 / 2}\right]$, a relation for SCLC method, where $\varepsilon_{\mathrm{r}}$ is the relative permittivity of the active layer (approximated to be 3.5), $\varepsilon_{0}$ is the permittivity of the vacuum, $\mu_{0}$ is the zero-field mobility, $L$ the thickness of the film, and $V$ the effective voltage, defined as the applied voltage minus the built-in voltage $\left(V_{\mathrm{bi}}\right)$ and the voltage loss due to series resistance $\left(V_{\mathrm{s}}\right)$.

\section{Funding Information}

The research has received funding from the Netherlands Organisation for Scientific Research via the NWO Spinoza grant awarded to R.A.J. Janssen. We further acknowledge funding from the Ministry of Education, Culture and Science (Gravity program 024.001.035). 


\section{Acknowledgment}

We thank Dr. P.J. Leenaers for recording gel permeation chromatograms.

\section{Supporting Information}

Supporting Information for this article is available online at https://doi.org/10.1055/s-0041-1726427.

\section{References}

(1) Mishra, A.; Bäuerle, P. Angew. Chem. Int. Ed. 2012, 51, 2020.

(2) Mishra, A.; Ma, C.-Q.; Bäuerle, P. Chem. Rev. 2009, 109, 1141.

(3) Li, Z.; Chueh, C.-C.; Jen, A. K.-Y. Prog. Polym. Sci. 2019, 99, 101175.

(4) Yan, C.; Barlow, S.; Wang, Z.; Yan, H.; Jen, A. K. Y.; Marder, S. R.; Zhan, X. Nat. Rev. Mater. 2018, 3, 18003.

(5) Lu, L.; Zheng, T.; Wu, Q.; Schneider, A. M.; Zhao, D.; Yu, L. Chem. Rev. 2015, 115, 12666.

(6) Yao, H.; Ye, L.; Zhang, H.; Li, S.; Zhang, S.; Hou, J. Chem. Rev. 2016, 116, 7397.

(7) Li, Y. Acc. Chem. Res. 2012, 45, 723.

(8) Liu, L.; Kan, Y.; Gao, K.; Wang, J.; Zhao, M.; Chen, H.; Zhao, C.; Jiu, T.; Jen, A. K. Y.; Li, Y. Adv. Mater. 2020, 32, 1907604.

(9) Ma, R.; Liu, T.; Luo, Z.; Guo, Q.; Xiao, Y.; Chen, Y.; Li, X.; Luo, S.; Lu, X.; Zhang, M.; Li, Y.; Yan, H. Sci. China Chem. 2020, 63, 325.

(10) Meng, L.; Zhang, Y.; Wan, X.; Li, C.; Zhang, X.; Wang, Y.; Ke, X.; Xiao, Z.; Ding, L.; Xia, R.; Yip, H. L.; Cao, Y.; Chen, Y. Science 2018, $361,1094$.

(11) Yao, J.; Qiu, B.; Zhang, Z. G.; Xue, L.; Wang, R.; Zhang, C.; Chen, S.; Zhou, Q.; Sun, C.; Yang, C.; Xiao, M.; Meng, L.; Li, Y. Nat. Commun. 2020, 11, 2726.

(12) Lin, Y.; Adilbekova, B.; Firdaus, Y.; Yengel, E.; Faber, H.; Sajjad, M.; Zheng, X.; Yarali, E.; Seitkhan, A.; Bakr, O. M.; El-Labban, A.; Schwingenschlögl, U.; Tung, V.; McCulloch, I.; Laquai, F.; Anthopoulos, T. D. Adv. Mater. 2019, 31, 1902965.

(13) Zhan, L.; Li, S.; Lau, T. K.; Cui, Y.; Lu, X.; Shi, M.; Li, C. Z.; Li, H.; Hou, J.; Chen, H. Energy Environ. Sci. 2020, 13, 635.

(14) Cui, Y.; Yao, H.; Zhang, J.; Xian, K.; Zhang, T.; Hong, L.; Wang, Y.; Xu, Y.; Ma, K.; An, C.; He, C.; Wei, Z.; Gao, F.; Hou, J. Adv. Mater. 2020, 32, 1908205.

(15) Liu, J.; Ma, L. K.; Li, Z.; Hu, H.; Sheong, F. K.; Zhang, G.; Ade, H.; Yan, H. J. Mater. Chem. A 2018, 6, 23270.

(16) Su, W.; Li, G.; Fan, Q.; Zhu, Q.; Guo, X.; Chen, J.; Wu, J.; Ma, W.; Zhang, M.; Li, Y. J. Mater. Chem. A 2019, 7, 2351.

(17) Qiu, B.; Chen, S.; Li, H.; Luo, Z.; Yao, J.; Sun, C.; Li, X.; Xue, L.; Zhang, Z. G.; Yang, C.; Li, Y. Chem. Mater. 2019, 31, 6558.

(18) Cui, C.; Li, Y. Energy Environ. Sci. 2019, 12, 3225.

(19) Casey, A.; Dimitrov, S. D.; Shakya-Tuladhar, P.; Fei, Z.; Nguyen, M.; Han, Y.; Anthopoulos, T. D.; Durrant, J. R.; Heeney, M. Chem. Mater. 2016, 28, 5110.

(20) Ayoub, S. A.; Lagowski, J. B. Phys. Chem. Chem. Phys. 2019, 21, 23978.
(21) Fan, Q.; Su, W.; Guo, X.; Wang, Y.; Chen, J.; Ye, C.; Zhang, M.; Li, Y. J. Mater. Chem. A 2017, 5, 9204.

(22) Bin, H.; Yao, J.; Yang, Y.; Angunawela, I.; Sun, C.; Gao, L.; Ye, L.; Qiu, B.; Xue, L.; Zhu, C.; Yang, C.; Zhang, Z. G.; Ade, H.; Li, Y. Adv. Mater. 2018, 30, 1706361.

(23) Feng, H.; Song, X.; Zhang, M.; Yu, J.; Zhang, Z.; Geng, R.; Yang, L.; Liu, F.; Baran, D.; Tang, W. Mater. Chem. Front. 2019, 3, 702.

(24) Bin, H.; Yang, Y.; Peng, Z.; Ye, L.; Yao, J.; Zhong, L.; Sun, C.; Gao, L.; Huang, H.; Li, X.; Qiu, B.; Xue, L.; Zhang, Z. G.; Ade, H.; Li, Y. Adv. Energy Mater. 2018, 8, 1702324.

(25) Li, Z.; Wu, F.; Lv, H.; Yang, D.; Chen, Z.; Zhao, X.; Yang, X. Adv. Mater. 2015, 27, 6999.

(26) Mo, D.; Chen, H.; Zhou, J.; Tang, N.; Han, L.; Zhu, Y.; Chao, P.; Lai, H.; Xie, Z.; He, F. J. Mater. Chem. A 2020, 8, 8903.

(27) Lee, S. K.; Seo, J. H.; Cho, N. S.; Cho, S. Thin Solid Films 2012, 520, 5438.

(28) Ye, L.; Zhang, S.; Zhao, W.; Yao, H.; Hou, J. Chem. Mater. 2014, 26 , 3603.

(29) Jo, M. Y.; Ha, Y. E.; Won, Y. S.; Yoo, S. Il; Kim, J. H. Org. Electron. 2015, 25, 85 .

(30) Jiang, J. M.; Lin, H. K.; Lin, Y. C.; Chen, H. C.; Lan, S. C.; Chang, C. K.; Wei, K. H. Macromolecules 2014, 47, 70.

(31) Zhang, J.; Zhu, X. W.; He, C.; Bin, H. J.; Xue, L. W.; Wang, W. G.; Yang, Y. K.; Yuan, N. Y.; Ding, J. N.; Wei, Z. X.; Zhang, Z. G.; Li, Y. F. J. Mater. Chem. A 2016, 4, 11747.

(32) Xue, L.; Yang, Y.; Xu, J.; Zhang, C.; Bin, H.; Zhang, Z. G.; Qiu, B.; Li, X.; Sun, C.; Gao, L.; Yao, J.; Chen, X.; Yang, Y.; Xiao, M.; Li, Y. Adv. Mater. 2017, 29, 1703344.

(33) Hu, Z.; Adachi, T.; Lee, Y. G.; Haws, R. T.; Hanson, B.; Ono, R. J.; Bielawski, C. W.; Ganesan, V.; Rossky, P. J.; Vanden Bout, D. A. ChemPhysChem 2013, 14, 4143.

(34) Zhang, Z. G.; Li, Y. Sci. China Chem. 2015, 58, 192.

(35) Cho, H. H.; Kim, T.; Kim, K.; Lee, C.; Kim, F. S.; Kim, B. J. J. Mater. Chem. A 2017, 5, 5449.

(36) Kini, G. P.; Jeon, S. J.; Moon, D. K. Adv. Mater. 2020, 32, 1906175.

(37) Sun, C.; Qin, S.; Wang, R.; Chen, S.; Pan, F.; Qiu, B.; Shang, Z.; Meng, L.; Zhang, C.; Xiao, M.; Yang, C.; Li, Y. J. Am. Chem. Soc. 2020, 142, 1465.

(38) Yao, H.; Qian, D.; Zhang, H.; Qin, Y.; Xu, B.; Cui, Y.; Yu, R.; Gao, F.; Hou, J. Chin. J. Chem. 2018, 36, 491.

(39) Karki, A.; Vollbrecht, J.; Dixon, A. L.; Schopp, N.; Schrock, M.; Reddy, G. N. M.; Nguyen, T. Q. Adv. Mater. 2019, 31, 1903868.

(40) Menke, S. M.; Ran, N. A.; Bazan, G. C.; Friend, R. H. Joule 2018, 2, 25.

(41) Bin, H.; Gao, L.; Zhang, Z. G.; Yang, Y.; Zhang, Y.; Zhang, C.; Chen, S.; Xue, L.; Yang, C.; Xiao, M.; Li, Y. Nat. Commun. 2016, 7, 13651.

(42) Saes, B. W. H.; Wienk, M. M.; Janssen, R. A. J. Chem. Eur. J. 2020 , 26,14221

(43) Bin, H.; Zhang, Z. G.; Gao, L.; Chen, S.; Zhong, L.; Xue, L.; Yang, C.; Li, Y. J. Am. Chem. Soc. 2016, 138, 4657.

(44) Kyaw, A. K. K.; Wang, D. H.; Gupta, V.; Leong, W. L.; Ke, L.; Bazan, G. C.; Heeger, A. J. ACS Nano 2013, 7, 4569.

(45) Bin, H.; Angunawela, I.; Ma, R.; Nallapaneni, A.; Zhu, C.; Leenaers, P. J.; Saes, B. W. H.; Wienk, M. M.; Yan, H.; Ade, H.; Janssen, R. A. J. J. Mater. Chem. C 2020, 8, 15426. 